\title{
BMJ Open Quitting experiences and preferences for a future quit attempt: a study among inpatient smokers
}

To cite: Thomas D, Abramson MJ, Bonevski B, et al. Quitting experiences and preferences for a future quit attempt: a study among inpatient smokers. BMJ Open 2015:5:e006959.

doi:10.1136/bmjopen-2014006959

- Prepublication history for this paper is available online To view these files please visit the journal online (http://dx.doi.org/10.1136/ bmjopen-2014-006959).

Received 20 0ctober 2014 Revised 5 February 2015 Accepted 6 February 2015

CrossMark

For numbered affiliations see end of article.

\section{Correspondence to}

Dr Johnson George; Johnson.George@monash. edu

\section{ABSTRACT}

Objective: Understanding smokers' quit experiences and their preferences for a future quit attempt may aid in the development of effective cessation treatments. The aims of this study were to measure tobacco use behaviour; previous quit attempts and outcomes; methods used to assist quitting; difficulties experienced during previous attempts; the motives and preferred methods to assist quitting in a future attempt; identify the factors associated with preferences for smoking cessation.

Design: Face-to-face interview using a structured questionnaire.

Setting: Inpatient wards of three Australian public hospitals.

Participants: Hospitalised smokers enrolled in a smoking cessation trial.

Results: Of 600 enrolled patients (42.8\% participation rate), $64.3 \%$ ( $n=386$ ) had attempted quitting in the previous 12 months. On a scale of 1 (low) to 10 (high), current motivation to quit smoking was high (median 9; IQR 6.5-10), but confidence was modest (median 5; IQR 3-8). Among 386 participants who reported past quit attempts, 69.9\% $(n=270)$ had used at least one cessation aid to assist quitting. Nicotine replacement therapy (NRT) was most commonly stated $(222,57.5 \%)$, although the majority had used NRT for $<4$ weeks. Hypnotherapy was the most common $(68,17.6 \%)$ non-pharmacological treatment. Over $80 \%(n=311)$ experienced withdrawal symptoms; craving and irritability were commonly reported. Most participants $(351,58.5 \%)$ believed medications, especially NRT $(322,53.7 \%)$, would assist them to quit in the future. History of previous smoking cessation medication use was the only independent predictor of interest in using medications for a future quit attempt.

Conclusions: The majority of smokers had attempted quitting in the previous 12 months; NRT was a popular cessation treatment, although it was not used as recommended by most. This suggests a need for assistance in the selection and optimal use of cessation aids for hospitalised smokers.

Trial registration number: Australian and New Zealand Clinical Trials Registry: ACTRN12612000368831.

\section{Strengths and limitations of this study}

Previous quitting experiences, and motives and preferences for a future quit attempt were assessed in a large sample of hospitalised smokers from three Australian public hospitals.

- Findings were based on self-report, which had limited validity and reliability. However, attempts were made to collect the most accurate information using trained research assistants who collected all the data face-to-face using a well-constructed and validated questionnaire.

- Participants rated highly on the readiness-to-quit ladder, and reported high motivation to quit, which may not be generalisable to all hospitalised patients. The study sample may represent a subset of hospitalised smokers eligible and interested in participating in a smoking cessation clinical trial.

\section{INTRODUCTION}

Hospitalisation provides an ideal opportunity for smokers to attempt to quit smoking. In Australia, many hospitals have implemented policies where smoking is not permitted indoors or within outdoor boundaries. ${ }^{1}$ This smoke-free environment gives patients an opportunity to attempt quitting away from their usual environmental smoking cues. At a time of feeling vulnerable regarding their health, patients may be motivated to quit smoking and become more receptive to smoking cessation messages and interventions. There is also substantial evidence to support the effectiveness of hospital-based smoking cessation interventions. ${ }^{2}$ A crosssectional study of hospitalised smokers found that many were interested in starting a smoking cessation intervention while in hospital. $^{3}$

Clinical practice guidelines for treating tobacco use and dependence within the hospital setting recommend the use of evidencebased smoking cessation aids to assist the quitting process. $^{4}$ Despite the fact that 
smoking cessation treatments, including counselling, ${ }^{5}$ nicotine replacement therapy (NRT) ${ }^{6}$ and other pharmacotherapies ${ }^{7}$ can significantly improve the odds of quitting, the use of such smoking cessation aids is modest. ${ }^{8}$ Only $3-5 \%$ of unaided quitting attempts are successful at 6 months, ${ }^{9}$ with smokers often relapsing because of withdrawal symptoms. ${ }^{410}$

Most smokers undertake numerous quit attempts. ${ }^{4}$ Understanding the process of quitting is important to optimise interventions. Additionally, there is a need to explore smokers' motives and preferences for methods to assist quitting, as many options and a wide range of products are available. ${ }^{11}$ Knowledge about previous quitting experiences and preferences for any future quit attempts could guide the selection of an appropriate strategy that is likely to help smokers quit, thus ensuring efficient use of clinicians' time and limited healthcare resources.

The main objective of this study was to explore the quitting experiences and preferences of smokers admitted to Australian public hospitals who volunteered to participate in a trial of a smoking cessation intervention targeting hospitalised smokers. Specifically, the study aimed: (1) to examine: (a) tobacco use behaviour, including previous quit attempts and outcomes; (b) methods used in the past 12 months to assist quitting; (c) self-reported difficulties experienced during previous quit attempts and side effects of pharmacotherapies; (d) the motives and preferred methods to assist quitting in any future quit attempts and (2) to identify the factors associated with preferences for smoking cessation.

\section{METHODS}

Baseline data were obtained from inpatients who were smokers at the time of hospital admission and enrolled in a randomised controlled trial (RCT) evaluating a smoking cessation intervention for hospitalised patients. Participants were recruited between April 2012 and June 2013 from inpatient wards of three Australian public hospitals in Victoria: The Alfred, Austin Health and Barwon Health. The detailed protocol of the RCT has been published elsewhere. ${ }^{12}$

Briefly, participants were 18 years of age or older, selfreported current (daily or occasional) smokers at the time of hospital admission, and available for 12 months of follow-up. Patients who were too ill (physically or mentally) to provide written informed consent or participate in the trial, unable to communicate in English, with a terminal illness, pregnant or already receiving active smoking cessation therapy at the time of hospital admission were excluded.

Potential participants were identified by active screening of hospital notes by a trained research assistant (RA) employed at each hospital. Pharmacists and other ward staff were informed about the research project and asked to refer all patients identified as current smokers, either from hospital records or from discussions with patients or other staff. The RA confirmed smoking status, assessed eligibility to participate, and provided a plain language statement describing the project to each potential participant. Written informed consent was obtained before proceeding with data collection. All information was collected face-to-face by the RA, using a pretested structured data collection form which incorporated validated scales. Data on comorbid conditions were extracted from hospital records. Age, sex, nicotine dependence and reason for non-participation were collected from non-consenting patients.

\section{Survey instruments}

Data were collected using a 32-item questionnaire. Items relevant to this study are as follows.

\section{Sociodemographic characteristics and comorbid conditions}

Sex, age, country of birth, education, employment and marital status, and current living arrangement were collected. Comorbid conditions were assessed using Charlson's comorbidity index, ${ }^{13}$ in which a weighted score was assigned to each of the 19 clinical conditions based on the relative risk of 1-year mortality. Higher scores indicated greater risk of death from comorbid conditions. The reason for hospital admission was obtained from the participants. The number of medications (both regular and as needed) at the time of hospital admission was collected from hospital records.

\section{Tobacco use and quitting behaviours}

Smoking status at the time of hospital admission (daily or occasional smoker) and age at which smoking was started were assessed. Previous quit attempts were determined by asking: 'Have you quit smoking for at least 1 day in the past 12 months?' If yes, the number of serious quit attempts (defined as smoke-free for at least $24 \mathrm{~h}$ ) in the past 12 months and the number of days smoke-free on the most recent quit attempt were assessed. Additionally, smoking habits of friends and housemates were explored.

Nicotine dependence was measured using the two-item Heaviness of Smoking Index (HSI), which assessed time to first cigarette after waking and number of cigarettes per day. ${ }^{14}$ The scores range from 0 to 6 with a score of 3 or less indicating 'light smokers', and 4 or more indicating 'heavy smokers'.

Stage of change was assessed using the readinessto-quit ladder with 10 response options. ${ }^{15}$ The stages were summarised as 'precontemplation'-not interested in quitting smoking in 6 months; 'contemplation'interested in quitting in 6 months; 'preparation'-interested in quitting in 1 month or already made changes in smoking habits; 'action'-already quit smoking.

Situational temptation to smoke was assessed using the nine-item smoking self-efficacy scale. ${ }^{16}$ Each situation was answered on a five-point Likert-type scale ranging from 'not at all tempted' to 'extremely tempted' to 
smoke, with scores ranging from 9 to 45 . Higher scores indicated greater smoking temptation.

Motivation to give up smoking was captured using a 10-point visual analogue scale (VAS) ${ }^{17}$ with 1 being 'very low' and 10 being 'very high'. Confidence in a participant's own ability to quit smoking was also measured using a 10-point VAS, ${ }^{17}$ with 1 being 'very low' and 10 being 'very high'.

\section{Difficulties experienced during the past quit attempts}

Participants were asked 'Have you experienced any difficulties during your past quit attempt?' If yes, they could choose one or more from the following options: increased appetite, poor concentration, urges to smoke, irritability or aggression, depression, mouth ulcers, restlessness, nighttime awaking and others. Participants were asked about any side effects from any of the smoking cessation medications they had used during past quit attempts. These questions were asked of only those who had attempted quitting in the previous 12 months.

\section{Methods used for cessation}

Participants were asked 'Have you used anything to assist quitting in the past?' If yes, specify, and the following options were listed: NRT, bupropion, varenicline, acupuncture, counselling, DVD or books, hypnotherapy, online programme, Quitline, quit smoking group and other. Use of different forms of NRT (patch, gum, lozenge, mini/microtab and inhaler) and dosage were also measured. These questions were only asked of those who had attempted to quit in the previous 12 months.

\section{Motives and preferences for a future quit attempt}

This was assessed by asking 'Which of the following would motivate/assist you to quit smoking?' with the following options listed: acupuncture, counselling, cash incentive, hypnotherapy, increasing prices of cigarettes, information on the amount of nicotine in your body, medication (bupropion, varenicline or NRT), plain packaging of cigarettes, personal contact with a healthcare professional, Quitline, smoking cessation groups and others. The preferred form of medication was assessed using the question 'If you had a choice of treatment to assist you to quit smoking, which form of medication would you prefer?' with the following options listed: tablet, sublingual tablet, patch, chewing gum, lozenge, inhaler, e-cigarette, unsure, 'I am not interested in medications' and other. Participants were also asked about the preferred strategy to quit smoking: 'If you decided to give up smoking now, which strategy would you adopt?' the options were: I am not thinking of quitting, I want to reduce gradually; 'cold turkey', I want to quit with the help of medicines, or other.

\section{Data analysis}

All analyses were conducted using the Statistical Package for Social Sciences (SPSS) (V.20.0; IBM, Armonk, New York, USA). The sociodemographic characteristics, tobacco use behaviour, methods used to assist in previous quit attempts, difficulties experienced, and motives and preferences for a future quit attempt were analysed descriptively and presented as mean $( \pm \mathrm{SD})$ or median $(\mathrm{IQR})$ or number (\%) based on type and distribution of data.

The demographic characteristics (age, sex, employment status, marital status, living arrangements, living with a smoker, having a smoker as a friend) of those who had tried quitting were compared with their counterparts, using $\chi^{2}$ or Student $t$ test. The age, sex and nicotine dependence of participants were compared with non-participants using $\chi^{2}$ or $t$ tests.

A logistic regression model was used to test the associations between participant characteristics (age, sex, education level, number of medications on admission, nicotine dependence, Charlson's index score, motivation to quit smoking, previous quitting failures, previous use of smoking cessation medications and experience of withdrawal symptoms during a previous quit attempt) and interest in using medications for a future quit attempt. All these variables were tested in univariable analyses first, and potential variables $(p<0.1)$ were entered into a multivariable model to test their independent associations. A higher $\alpha$ level (10\%) was used in univariable analyses to identify all potential confounding variables. Preferences for a future quit attempt of various subgroups stratified by sex, age, nicotine dependence were tested using $\chi^{2}$ test. A $\mathrm{p}$ value $<0.05$ was considered statistically significant.

\section{RESULTS}

The mean participation rate in the RCT was $42.8 \%$ across the three sites (participation rates at the individual hospitals ranged from $35.4 \%$ to $49.6 \%$ ) giving a final sample size of 600 participants (figure 1). Nonparticipants were more likely to be light smokers $(72.0 \%$ vs $52.7 \%, \mathrm{p}<0.001)$ and slightly older $(53.1 \pm 16.7$ vs $51.0 \pm 14.1$ years, $\mathrm{p}=0.012$ ) than participants. The demographic characteristics of the study participants are presented in table 1.

The common reasons for hospital admission selfreported by participants were disorders of the circulatory system $(135,22.5 \%)$, musculoskeletal system and connective tissue $(97,16.2 \%)$, respiratory system (75, $12.5 \%)$, digestive system $(67,11.2 \%)$ and nervous system $(65,10.8 \%)$. The median Charlson's index score was 1 (IQR 0-2) and the median number of medications used at the time of hospital admission was 4 (IQR 1-7).

\section{Tobacco use and quitting behaviour}

Tobacco use behaviours are outlined in table 2. The majority of participants were daily smokers and the median age at which smoking was started was 15 (IQR 13-18) years. Three-quarters of participants were either in the 'preparation' or 'action stage' on the readiness-to-quit ladder. Motivation to quit smoking was high (median 9; IQR 6.5-10), although confidence 
Figure 1 Diagram outlining patient recruitment.
2677 hospitalised patients assessed for study eligibility

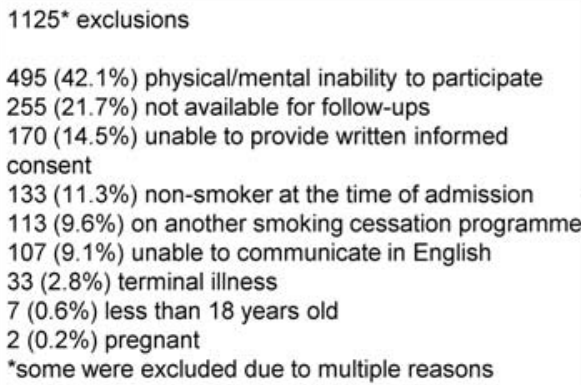

"some were excluded due to multiple reasons

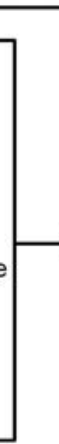

was modest (median 5; IQR 3-8). The mean self-efficacy score, evaluating temptation to smoke, was $33.03( \pm 7.86)$.

Almost two-thirds $(386,64.3 \%)$ of participants had tried quitting at least once during the previous 12 months; $43.2 \%$ reported multiple quit attempts. The median number of serious quit attempts (abstinent for $24 \mathrm{~h}$ or longer) in the previous 12 months was 2 (IQR 1-4) and the median number of days smoke-free on the most recent attempt was 4 (IQR 2-14). There were no statistically significant differences between the characteristics of those who had at least one quit attempt and those who did not.

600 completed baseline survey and included in this study

Difficulties experienced during quit attempts in the past 12 months

Of the 386 participants who tried quitting in the previous 12 months, $80.6 \%(\mathrm{n}=311)$ reported experiencing at least one difficulty or withdrawal symptom during their quit attempts; $67.1 \%(n=259)$ reported having multiple difficulties. Self-reported difficulties are detailed in table 3. Among the users of NRT, varenicline or bupropion $(n=249)$, more than half $(141,56.6 \%)$ had experienced side effects.

\section{Methods used to quit smoking}

Of those who tried quitting in the previous 12 months $(n=386), 69.9 \%$ had used at least one method (either

Table 1 Demographic characteristics of the study participants

\begin{tabular}{|c|c|c|c|c|}
\hline & \multicolumn{4}{|c|}{ Number $(\%)$ or mean ( $(\mathrm{SD})$} \\
\hline & Hospital $1(n=200)$ & Hospital $2(n=200)$ & Hospital $3(n=200)$ & Overall $(n=600)$ \\
\hline Age, mean $( \pm S D)$ years & $49.6( \pm 14.4)$ & $52.3( \pm 14.0)$ & $51.14( \pm 13.8)$ & $51.0( \pm 14.1)$ \\
\hline Sex, male & $142(71.0 \%)$ & $122(61.0 \%)$ & $120(60.0 \%)$ & $384(64.0 \%)$ \\
\hline Born in Australia & $148(74.0 \%)$ & $162(81.0 \%)$ & $171(85.5 \%)$ & 481 (80.2\%) \\
\hline Mainly speaks English at home & $183(91.5 \%)$ & $191(95.5 \%)$ & $196(98.0 \%)$ & $570(95.0 \%)$ \\
\hline \multicolumn{5}{|l|}{ Education } \\
\hline Primary school or below & $6(3.0 \%)$ & $9(4.5 \%)$ & $8(4.0 \%)$ & $23(3.8 \%)$ \\
\hline Secondary school & $108(54.0 \%)$ & $120(60.0 \%)$ & $136(68.0 \%)$ & $364(60.7 \%)$ \\
\hline Technical or further education & $47(23.5 \%)$ & $30(15.0 \%)$ & $40(20.0 \%)$ & $117(19.5 \%)$ \\
\hline University & $39(19.5 \%)$ & $41(20.5 \%)$ & $16(8.0 \%)$ & $96(16.0 \%)$ \\
\hline \multicolumn{5}{|l|}{ Employment status } \\
\hline Employed-full/part time & $94(47.0 \%)$ & $92(46.0 \%)$ & $92(46.0 \%)$ & $278(46.3 \%)$ \\
\hline Retired/pensioner & $48(24.0 \%)$ & $50(25.0 \%)$ & $49(24.5 \%)$ & $147(24.5 \%)$ \\
\hline Unemployed/home duties/student & $35(17.5 \%)$ & $41(20.5 \%)$ & $24(12.0 \%)$ & $100(16.7 \%)$ \\
\hline Disabled/unable to work & $23(11.5 \%)$ & $17(8.5 \%)$ & $35(17.5 \%)$ & 75 (12.5\%) \\
\hline \multicolumn{5}{|l|}{ Marital status } \\
\hline Married/de-facto/engaged & $78(39.0 \%)$ & $89(44.5 \%)$ & $97(48.5 \%)$ & $264(44.0 \%)$ \\
\hline Never married/single & $62(31.0 \%)$ & $44(22.0 \%)$ & $28(14.0 \%)$ & $134(22.3 \%)$ \\
\hline Separated/divorced/widowed & $60(30.0 \%)$ & $67(33.5 \%)$ & $75(37.5 \%)$ & $202(33.7 \%)$ \\
\hline \multicolumn{5}{|l|}{ Current living arrangements } \\
\hline Family household & $111(55.5 \%)$ & $148(74.0 \%)$ & $140(70.0 \%)$ & $399(66.5 \%)$ \\
\hline Single-person household & $66(33.0 \%)$ & $41(20.5 \%)$ & $48(24.0 \%)$ & $155(25.8 \%)$ \\
\hline Group household & $21(10.5 \%)$ & $8(4.0 \%)$ & $8(4.0 \%)$ & $37(6.2 \%)$ \\
\hline Residential facility & $2(1.0 \%)$ & $3(1.5 \%)$ & $4(2.0 \%)$ & $9(1.5 \%)$ \\
\hline
\end{tabular}


Table 2 Tobacco use behaviour $(n=600)$

\begin{tabular}{|c|c|}
\hline Tobacco use behaviour & $\begin{array}{l}\text { Number (\%) or } \\
\text { Median (IQR) }\end{array}$ \\
\hline Daily smokers & $575(95.8)$ \\
\hline Heavy smokers (HSI $\geq 3$ ) & $284(47.3)$ \\
\hline $\begin{array}{l}\text { Number of years of smoking, } \\
\text { median (IQR) }\end{array}$ & $35(24-45)$ \\
\hline Have a smoker as friend & $519(86.5)$ \\
\hline Lives with a smoker & $236(39.3)$ \\
\hline \multicolumn{2}{|l|}{ Position on readiness-to-quit ladder ${ }^{\dagger}$} \\
\hline Pre-contemplation & $103(17.2)$ \\
\hline Contemplation & $40(6.7)$ \\
\hline Preparation & $338(56.3)$ \\
\hline Action* & $117(19.5)$ \\
\hline $\begin{array}{l}\text { Current motivation to give up } \\
\text { smoking, Median (IQR) }\end{array}$ & $9(6.5-10)$ \\
\hline $\begin{array}{l}\text { Current confidence in giving up } \\
\text { smoking, Median (IQR) }\end{array}$ & $5(3-8)$ \\
\hline \multicolumn{2}{|c|}{$\begin{array}{l}\text { ¿Participants began their quit period once admitted to hospita } \\
\text { tHave missing values two participants. } \\
\text { FHave missing values five participants. } \\
\text { S Have missing values six participants. } \\
\text { HSI, Heaviness of Smoking Index. }\end{array}$} \\
\hline
\end{tabular}

pharmacological or non-pharmacological support) to assist their quit attempts. More than half $(57.5 \%)$ had tried at least one form of NRT; one in five participants $(20.0 \%)$ had tried different forms of NRT. Almost one-third $(29.3 \%)$ had used prescription smoking cessation medications (varenicline or bupropion) to assist quitting; varenicline was the most frequently used (24.4\%). Hypnotherapy $(17.6 \%)$ was the most commonly tried non-pharmacological method, followed by contacting Quitline (13.2\%).

Among users of NRT $(n=222)$, patches were the most used form. Of the 75 participants who provided information about the duration of NRT usage (nicotine patch), over $80 \%(\mathrm{n}=61)$ used them for less than 4 weeks, and

\begin{tabular}{lc}
$\begin{array}{l}\text { Table } 3 \\
(\mathrm{n}=386)\end{array}$ & Difficulties experienced during past quit attempts \\
\hline & Number (\%) \\
\hline Number of participants experiencing & $311(80.6)$ \\
difficulties* & \\
Urge to smoke & $229(59.3)$ \\
Irritability/aggression & $201(52.1)$ \\
Restlessness & $183(47.4)$ \\
Increased appetite & $155(40.2)$ \\
Nighttime awakenings & $126(32.6)$ \\
Depression & $101(26.2)$ \\
Poor concentration & $91(23.6)$ \\
Mouth ulcers & $23(6.0)$ \\
Anxiety & $7(1.8)$ \\
Weight gain & $5(1.3)$ \\
Night sweats & $3(0.8)$ \\
Others & $24(6.3)$ \\
\hline *Some experienced more than one difficulty. &
\end{tabular}

Table 4 Methods used for quitting in the previous 12 months $(n=386)$

\begin{tabular}{lc}
\hline Method used* & Number (\%) \\
\hline Nicotine replacement therapy & $222(57.5)$ \\
Patch & $196(50.8)$ \\
Gum & $75(19.4)$ \\
Lozenge & $27(7.0)$ \\
Inhaler & $24(6.2)$ \\
Sublingual tablet & $19(4.9)$ \\
Prescription medication & $113(29.3)$ \\
Varenicline & $94(24.4)$ \\
Bupropion & $31(8.0)$ \\
Non-pharmacological treatment & \\
Hypnotherapy & $68(17.6)$ \\
Quitline & $51(13.2)$ \\
Acupuncture & $22(5.7)$ \\
Counselling & $18(4.7)$ \\
e-cigarette & $17(4.4)$ \\
DVD or books & $15(3.9)$ \\
Online programme & $7(1.8)$ \\
Quit smoking group & $7(1.8)$ \\
Other methods & $16(4.1)$ \\
\hline
\end{tabular}

*Some participants used more than one method in their past quit attempts.

$56 \%(\mathrm{n}=42)$ reported using them for 1 week or less. Only $14.7 \% \quad(n=11)$ used NRT for the recommended duration of 8 weeks or more. Different methods used to assist quitting are presented in table 4 .

Motives and preferences for a future quit attempt

More than half the participants $(58.5 \%)$ believed that medication would assist them to quit; the most cited

Table 5 Motives and preferences for a future quit attempt $(n=600)^{*}$

\begin{tabular}{ll}
\hline & Number (\%) \\
\hline Medication & $351(58.5)$ \\
Nicotine replacement therapy & $322(53.7)$ \\
Varenicline & $186(31.0)$ \\
$\quad$ Bupropion & $159(26.5)$ \\
Cash incentive & $268(44.7)$ \\
Hypnotherapy & $251(41.8)$ \\
Personal contact with healthcare provider & $207(34.5)$ \\
Acupuncture & $179(29.8)$ \\
Increasing prices of cigarettes & $169(28.2)$ \\
Counselling & $159(26.5)$ \\
Information on amount of nicotine in body & $158(26.3)$ \\
Smoking cessation group & $123(20.5)$ \\
Quitline & $110(18.3)$ \\
Health benefit & $74(12.3)$ \\
Plain packaging of cigarettes & $41(6.8)$ \\
Others & $73(12.2)$
\end{tabular}

Some participants reported multiple motives/preferences for a future quit attempt.

*Data missing for two participants. 
Table 6 Interest in use of medications ${ }^{*}$ for a future quit attempt by subgroups (univariable results)

\begin{tabular}{|c|c|c|c|c|}
\hline & Interested & Not-interested & p Value & OR $(95 \% \mathrm{Cl})$ \\
\hline \multicolumn{5}{|l|}{ Sex } \\
\hline Female & $133(61.6 \%)$ & $83(38.4 \%)$ & & \\
\hline Male & $218(56.8 \%)$ & $166(43.2 \%)$ & 0.201 & $0.80(0.57$ to 1.13$)$ \\
\hline \multicolumn{5}{|l|}{ Age (years) } \\
\hline$\leq 51$ & $178(59.1 \%)$ & $123(40.9 \%)$ & & \\
\hline$>51$ & $173(57.9 \%)$ & $126(42.1 \%)$ & 0.751 & 0.95 (0.69 to 1.31$)$ \\
\hline \multicolumn{5}{|l|}{ Nicotine dependence } \\
\hline Light smokers & $173(54.7 \%)$ & $143(45.3 \%)$ & & \\
\hline Heavy smokers & $178(62.7 \%)$ & $106(37.3 \%)$ & 0.049 & 1.39 (1.001 to 1.93$)$ \\
\hline \multicolumn{5}{|l|}{ Education } \\
\hline No education or below year 12 & $241(62.3 \%)$ & $146(37.7 \%)$ & & \\
\hline Above year 12 or technical education & $110(51.6 \%)$ & $103(48.4 \%)$ & 0.012 & 0.65 (0.46 to 0.91$)$ \\
\hline \multicolumn{5}{|l|}{ Previous use of medication } \\
\hline No & $191(54.4 \%)$ & $160(66.4 \%)$ & & \\
\hline Yes & $160(64.3 \%)$ & $89(45.6 \%)$ & 0.016 & 1.51 (1.08 to 2.10$)$ \\
\hline \multicolumn{5}{|l|}{ Previous withdrawal symptoms } \\
\hline No & $34(47.9 \%)$ & $37(52.1 \%)$ & & \\
\hline Yes & $183(58.8 \%)$ & $128(41.2 \%)$ & 0.094 & $1.56(0.93$ to 2.61$)$ \\
\hline
\end{tabular}

medication was NRT (table 5). Nearly half the participants were interested in cash incentives. Hypnotherapy and acupuncture were also popular options.

Almost two-thirds of past NRT users and $42 \%$ of non-NRT medication (bupropion, varenicline) users were interested in reusing those medications in their future quit attempts. Previous quitting failures, number of medications on admission, Charlson's index score or current motivation to quit smoking were not associated with interest in using smoking cessation medications for a future quit attempt (data not shown). Likewise, age, sex and previous withdrawal symptoms were not associated with preferences in using medications for a future quit attempt. Interest in using medications for a future quit attempt of various subgroups is presented in table 6 . In a multivariable model, only previous use of smoking cessation medication (OR 2.21; CI 1.43 to 3.42; $\mathrm{p}<0.001$ ) was independently associated with interest in using medications for a future quit attempt.

Significantly higher proportions of women compared with men reported interest in using hypnotherapy $(48.1 \%$ vs $38.5 \%, \mathrm{p}=0.023)$, acupuncture $(35.0 \%$ vs $27.1 \%$, $\mathrm{p}=0.042)$, Quitline (25.2\% vs $14.6 \%, \mathrm{p}=0.001)$, and having personal contact with a healthcare provider $(40.7 \%$ vs $31.3 \%, \mathrm{p}=0.02)$ for a future quit attempt. Likewise, a higher proportion of younger smokers ( $\leq 51$ years) compared with older smokers ( $>51$ years) were interested in hypnotherapy ( $48.3 \%$ vs $35.6 \%, \mathrm{p}=0.002)$, acupuncture $(36.7 \%$ vs $23.2 \%, \mathrm{p}<0.001)$, and cash incentives $(51.7 \%$ vs $37.9 \%, \mathrm{p}=0.001$ ) for a future quit attempt.

The most widely selected strategy to give up smoking was 'quit with the help of medicines' (49.5\%), followed by 'cold turkey' (33.5\%), and 'reduce gradually' (13.3\%). Nicotine patches $(54.2 \%)$ were the preferred form to assist quitting, followed by tablets $(45.0 \%)$, inhalers $(40.8 \%)$, lozenges
(34.7\%), electronic 'cigarettes' (e-cigarette) (32.3\%), chewing gum $(27.0 \%)$ and sublingual tablets $(23.0 \%)$.

\section{DISCUSSION}

This paper describes the baseline characteristics of a diverse sample of hospitalised smokers enrolled in a multicentre RCT of a smoking cessation intervention. Almost two-thirds of our study population were male. The majority of participants had high motivation to quit, despite failing in their past quit attempts, and experiencing various withdrawal symptoms. Most smokers in this study were interested in using some form of smoking cessation support in a future quit attempt. Previous use of smoking cessation medication use was the only factor independently associated with interest in using medications for a future quit attempt.

Hospitalisation is an ideal opportunity for health professionals to assist people to quit smoking. Previous studies have reported high motivation among inpatients to quit smoking. ${ }^{3}{ }^{18}$ These motivated smokers may be more receptive to smoking cessation messages and more likely to quit than their counterparts. A hospitalised smoker will be under the care of multiple health professionals who could provide quitting assistance. According to a survey of past smokers, being asked about smoking by two or more types of health professionals substantially increased the odds of quitting and readiness to quit. ${ }^{19}$ When patients are in hospital, health professionals can make use of the opportunity to offer pharmacotherapy and/or non-pharmacotherapy cessation modalities. The smoke-free policies of hospitals should include cessation support to every patient. Smoking cessation support services should be included in the designated duties of health professionals. 
More than half of our participants wanted to try medications in their future attempts to quit. This included past users of NRT and non-NRT medications. A previous study conducted in emergency departments also reported similar magnitude of interest in medications to assist in future quit attempts. ${ }^{20}$ However, one-third of our study participants wanted to quit 'cold turkey', without any aids. Although two-thirds to three-quarters of ex-smokers eventually stop unaided, this is associated with some of the lowest success rates. ${ }^{9} 21$ The clinical practice guidelines for treating tobacco use and dependence recommend offering counselling and medication to all smokers willing to quit, as this combination can double the chances of quitting. ${ }^{4}$ Even though many of our study participants had used medications during their previous quit attempts, only a few used them for the recommended duration. Moreover, the majority experienced difficulties or withdrawal symptoms during their past quit attempts, and more than half experienced side effects from medications. Consistent with a previous report, ${ }^{22}$ most participants reported relapsing within 1 week of their most recent quit attempt. These highlight the importance of coupling pharmacotherapy with counselling and behavioural strategies for dealing with withdrawal symptoms. Within the hospital setting, behavioural counselling could be offered opportunistically by health professionals, trained smoking cessation counsellors, or through referral to other services such as the telephone Quitline. Patients can also be closely monitored for any side effects from smoking cessation medications.

Complementary and alternative therapies such as hypnotherapy and acupuncture are yet to prove their efficacy $^{23} 24$ in smoking cessation, but were popular smoking cessation methods especially among women and younger participants. Almost $18 \%$ of participants reported using hypnotherapy in the past, and $42 \%$ were interested to use it in their future quit attempts. There is insufficient evidence to recommend hypnotherapy as a smoking cessation treatment. ${ }^{23}$ Similarly only a small proportion had used acupuncture in past attempts, but a larger proportion was interested to use this in their future quit attempts. The effectiveness of acupuncture is inconclusive and likely to be less than nicotine gum. ${ }^{24}$ Despite the proven effectiveness of brief-intensive counselling, ${ }^{5}$ only about one-quarter of participants were interested in counselling. A substantial proportion of participants were interested in personal contact with healthcare providers, information about the amount of nicotine in the body, and joining smoking cessation groups. The benefits of evidence-based treatments need to be reinforced to patients.

Interest in the use of e-cigarettes to help the quitting process is increasing. ${ }^{25}$ Although less than $5 \%$ of our sample reported using e-cigarettes in their previous quit attempts, almost one-third reported an interest in using e-cigarettes in their future attempts. A recent study comparing the effectiveness of e-cigarettes and nicotine patches found similar abstinence rates at 6 months. ${ }^{26}$ However, the role of e-cigarettes in tobacco control is uncertain, especially in countries such as Australia where retailing of e-cigarettes is prohibited. ${ }^{27}$ In the UK and European Union, their use is being regulated ${ }^{28}$ partly due to an increase in their uptake among nonsmoking adolescents. ${ }^{29}$ Long-term safety data are still emerging. Further evidence is required before promoting e-cigarettes for smoking cessation.

Many participants believed that increasing the price of cigarettes would motivate them to quit. Increasing prices is recognised as the most effective way to control tobacco consumption. ${ }^{30}$ In Europe, a 5-7\% decrease of cigarette consumption was observed with a $10 \%$ increase in the price of cigarettes. ${ }^{31}$ Similar trends have been observed in Australia ${ }^{32}$ and the USA. ${ }^{33}$ Nearly half of the smokers were interested in cash incentives. Even though a large RCT confirmed the long-term effectiveness of incentives in smoking cessation, ${ }^{34}$ more research is required before its adoption into routine clinical practice, as these interventions may work only in certain situations. ${ }^{35}$

Findings from our study suggest that smokers have different preferences, and many of them are interested in assistance with their future quit attempts. Individually tailoring interventions to match smokers' needs and preferences may enhance treatment outcomes. ${ }^{11}$ Healthcare providers should consider the experiences of smokers in past quit attempts, discuss available options to assist quitting, and consider patient preferences before recommending a therapy. There is a clear need for patient education regarding evidence-based treatments, and the implications of using unproven treatments should also be explained.

To the best of our knowledge, this is the first, large-scale, multicentre study assessing previous quitting experiences, and motives and preferences for a future quit attempt among hospitalised smokers. However, the study has some limitations. These results should be interpreted with some caution as the study participation rate was less than $50 \%$ and the sample may not represent all hospitalised smokers. Smokers with acute psychiatric conditions, or who were critically ill, were excluded from the study. The rate of self-reported quit attempts in the previous 12 months in our cohort was more than double the national average of $29 \% .{ }^{36}$ This may be due to participation bias, as the study sample might have had a greater interest in quitting. Our participants rated highly on the readiness-to-quit ladder, and reported high motivation to quit. Also, many of them were admitted for cardiorespiratory disorders for which smoking is a major risk factor, which may have increased their motivation to quit. Of the 802 patients who declined to participate in the study, 284 declined because they were not interested in quitting, suggesting low motivation among these patients. Our results, therefore, may not be generalisable to smokers disinterested in quitting. However, interest in quitting was not an eligibility criterion for our study. Moreover, 103 of the 600 participants were in the 
precontemplation stage and had not yet decided whether they wanted to quit smoking. It is also possible that there was a degree of social desirability bias among participants given all the data were collected by selfreport. Inaccuracies in some measures may also have occurred due to recall bias. However, data were collected by trained research assistants who were not involved in the care of participants, and attempts were made to use well-constructed and validated self-report items.

\section{CONCLUSION}

The majority of hospitalised smokers had attempted quitting in the previous 12 months. NRT was a popular cessation treatment prior to hospitalisation, although it was frequently not used as recommended. High motivation, but modest confidence to quit among smokers and a history of withdrawal symptoms and side effects from smoking cessation medications during past quit attempts, suggests the need for greater support for hospitalised smokers interested in quitting. This reinforces the importance of appropriate use of smoking cessation aids and assistance from suitably trained health professionals at the time of initiating smoking cessation medications and in their ongoing monitoring. Screening the smoking status of all patients, initiation of appropriate smoking cessation intervention and adequate postdischarge follow-up should be integrated into routine clinical practice at hospitals implementing a 'smoke-free' policy.

\section{Author affiliations}

${ }^{1}$ Faculty of Pharmacy and Pharmaceutical Sciences, Centre for Medicine Use and Safety, Monash University (Parkville Campus), Parkville, Victoria, Australia ${ }^{2}$ Department of Epidemiology \& Preventive Medicine, Faculty of Medicine, Nursing and Health Sciences, Monash University, The Alfred, Melbourne, Victoria, Australia

${ }^{3}$ School of Medicine \& Public Health, Faculty of Health \& Medicine, University of Newcastle, Callaghan, New South Wales, Australia

${ }^{4}$ Pharmacy Department, Austin Health, Heidelberg, Victoria, Australia

${ }^{5}$ Pharmacy Department, The Alfred, Prahran, Victoria, Australia

${ }^{6}$ Pharmacy Department, Barwon Health, Geelong, Victoria, Australia

Acknowledgements The authors thank all the intervention pharmacists and research assistants; Salma Attie, Sue Baulch, Emma Dean, Loan Huynh, Marissa Izzard, Josephine McGuiness and Hala Merola. BB was supported by a Cancer Institute NSW Career Development Fellowship.

Contributors JG conceived the idea. DT, MJA, BB, ST, SGP, GRW and MJD contributed to the design and conduct of the study. DT carried out the statistical analysis and drafted the original manuscript. All authors contributed in interpreting the data and critically revising the manuscript, and provided approval of the final manuscript.

Funding This work was supported by the Australian Research Council through the Linkage Scheme (LP110200724) and an investigator-initiated research (IIR) grant from Pfizer.

Competing interests JG, MJA and BB hold an IIR grant from BoehringerIngelheim. MJA was a member of the Scientific Committee for a workshop on an unrelated topic that was sponsored by GlaxoSmithKline, but did not receive any honorarium. He has undertaken an unrelated consultancy for AstraZeneca. He received an honorarium for speaking at a Novartis Respiratory Symposium.
Ethics approval The study was approved by the Human Research Ethics Committees of all three participating hospitals and Monash University.

Provenance and peer review Not commissioned; externally peer reviewed.

Data sharing statement No additional data are available.

Open Access This is an Open Access article distributed in accordance with the Creative Commons Attribution Non Commercial (CC BY-NC 4.0) license, which permits others to distribute, remix, adapt, build upon this work noncommercially, and license their derivative works on different terms, provided the original work is properly cited and the use is non-commercial. See: http:// creativecommons.org/licenses/by-nc/4.0/

\section{REFERENCES}

1. Freund $M$, Campbell $E$, Paul $C$, et al. Smoking care provision in smoke-free hospitals in Australia. Prev Med 2005;41:151-8.

2. Rigotti NA, Clair C, Munafo MR, et al. Interventions for smoking cessation in hospitalised patients. Cochrane Database Syst Rev 2012;(5):CD001837.

3. George J, Taylor S, Hong T, et al. A pilot study to investigate the scope for an in-patient smoking cessation program. Intern Med $J$ 2012;42:e80-3.

4. Fiore MC, Jane CR, Baker TB, et al. Treating tobacco use and dependence: 2008 update. Clinical practice guideline. Rockville, MD Department of Health and Human Services, Public Health Service, 2008.

5. Stead LF, Buitrago D, Preciado N, et al. Physician advice for smoking cessation. Cochrane Database Syst Rev 2013;(5): CD000165.

6. Stead LF, Perera R, Bullen C, et al. Nicotine replacement therapy for smoking cessation. Cochrane Database Syst Rev 2012;(11): CD000146.

7. Cahill K, Stevens S, Perera R, et al. Pharmacological interventions for smoking cessation: an overview and network meta-analysis. Cochrane Database Syst Rev 2013;5:CD009329.

8. Centers for Disease Control and Prevention. Quitting smoking among adults-United States, 2001-2010. MMWR Morb Mort Wkly Rep 2011;60:1513-19.

9. Hughes JR, Keely J, Naud S. Shape of the relapse curve and long-term abstinence among untreated smokers. Addiction 2004;99:29-38.

10. Foulds J, Ghodse H. Treating tobacco dependence. Adv Psychiatr Treat 1995;1:116-23.

11. McClure JB, Swan GE. Tailoring nicotine replacement therapy. CNS Drugs 2006;20:281-91.

12. Thomas D, Abramson MJ, Bonevski B, et al. A pharmacist-led system-change smoking cessation intervention for smokers admitted to Australian public hospitals (GIVE UP FOR GOOD): study protocol for a randomised controlled trial. Trials 2013;14:148.

13. Charlson ME, Pompei P, Ales KL, et al. A new method of classifying prognostic comorbidity in longitudinal studies: development and validation. J Chronic Dis 1987;40:373-83.

14. Borland R, Yong $\mathrm{HH}$, O'Connor RJ, et al. The reliability and predictive validity of the Heaviness of Smoking Index and its two components: findings from the International Tobacco Control Four Country study. Nicotine Tob Res 2010;12(Supp 1):S45-50.

15. Niaura R, Shadel WG, Niaura R, et al. Assessment to inform smoking cessation treatment. In: Abrams DB, Niaura R, Brown RA, et al. The tobacco dependence treatment handbook: a guide to best practices. New York: Guilford Press, 2003:33.

16. Velicer WF, DiClemente CC, Rossi JS, et al. Relapse situations and self-efficacy: an integrative model. Addict Behav 1990;15:271-83.

17. Rollnick S, Butler CC, Stott N. Helping smokers make decisions: the enhancement of brief intervention for general medical practice. Patient Educ Couns 1997;31:191-203.

18. Faseru B, Turner M, Casey G, et al. Evaluation of a hospital-based tobacco treatment service: outcomes and lessons learned. J Hosp Med 2011;6:211-18.

19. An LC, Foldes SS, Alesci NL, et al. The impact of smokingcessation intervention by multiple health professionals. Am J Prev Med 2008;34:54-60.

20. Choo EK, Sullivan AF, LoVecchio F, et al. Patient preferences for emergency department-initiated tobacco interventions: a multicenter cross-sectional study of current smokers. Addict Sci Clin Pract 2012;7:1-9.

21. Chapman S, Mackenzie R. The global research neglect of unassisted smoking cessation: causes and consequences. PLOS Med 2010;7:e1000216. 
22. UW Center for Tobacco Research and Intervention. How Smokers Are Quitting: Action Paper Number 3: University of Wisconsin Center for Tobacco Research and Intervention, the UW Comprehensive Cancer Center's Monitoring and Evaluation Program and the Wisconsin Tobacco Control Board. 2003.

23. Barnes J, Dong CY, McRobbie $\mathrm{H}$, et al. Hypnotherapy for smoking cessation. Cochrane Database Syst Rev 2010(10):CD001008.

24. White AR, Rampes H, Liu JP, et al. Acupuncture and related interventions for smoking cessation. Cochrane Database Syst Rev 2014;(1):CD000009.

25. Action on Smoking and Health. Use of e-cigarettes in Great Britain among adults and young people: ASH fact sheet. ASH, 2013.

26. Bullen $\mathrm{C}$, Howe $\mathrm{C}$, Laugesen $\mathrm{M}$, et al. Electronic cigarettes for smoking cessation: a randomised controlled trial. Lancet 2013;382:1629-37.

27. Therapeutic goods administration. Electronic cigarettes 2011 Department of Health. http://www.tga.gov.au/industry/devices-basics. htm (accessed 5 Aug 2014).

28. The Lancet Respiratory Medicine. E-cigarettes-too fast, too young? Lancet Respir Med 2014;2:1.

29. Centers for Disease Control and Prevention. Notes from the field: electronic cigarette use among middle and high school students-
United States, 2011-2012. MMWR Morb Mortal Wkly Rep 2013:729-30.

30. World Health Organization. WHO Report on the Global Tobacco Epidemic 2008: the MPOWER package. Geneva: World Health Organization, 2008

31. Gallus S, Schiaffino A, La Vecchia C, et al. Price and cigarette consumption in Europe. Tob Control 2006;15:114-9.

32. Dunlop SM, Perez D, Cotter T. Australian smokers' and recent quitters' responses to the increasing price of cigarettes in the context of a tobacco tax increase. Addiction 2011;106:1687-95.

33. Centers for Disease Control and Prevention. Response to increases in cigarette prices by race/ethnicity, income, and age groupsUnited States, 1976-1993. MMWR Morb Mortal Wkly Rep 1998:605-9.

34. Volpp KG, Troxel AB, Pauly MV, et al. A randomized, controlled trial of financial incentives for smoking cessation. $N$ Engl J Med 2009;360:699-709.

35. Cahill K, Perera R. Competitions and incentives for smoking cessation. Cochrane Database Syst Rev 2011(4):CD004307.

36. Australian Institute of Health and Welfare. 2010 National Drug Strategy Household Survey report. Canberra: Australian Institute of Health and Welfare, 2011. 